\title{
The immediate effect of soft tissue manual therapy intervention on lung function in severe chronic obstructive pulmonary disease
}

This article was published in the following Dove Press journal:

International Journal of COPD

21 February 2017

Number of times this article has been viewed

\section{Carlos Cruz-Montecinos ${ }^{1-3}$ \\ Diego Godoy-Olave ${ }^{4}$ \\ Felipe A Contreras-Briceño 5 \\ Paulina Gutiérrez ${ }^{4}$ \\ Rodrigo Torres-Castro ${ }^{2}$ \\ Leandro Miret-Venegas ${ }^{3}$ \\ Roger M Engel ${ }^{6}$}

'Laboratory of Biomechanics and Kinesiology, San José Hospital,

Santiago, Chile; ${ }^{2}$ Department of Physical Therapy, Faculty of Medicine, University of Chile, Santiago, Chile;

${ }^{3}$ Unit of Kinesiology and Physical

Therapy, San José Hospital, Santiago,

Chile; ${ }^{4}$ Departamento de Kinesiología,

Universidad Metropolitana de

Ciencias de la Educación, Santiago,

Chile; ${ }^{5}$ Facultad de Medicina, Pontificia

Universidad Católica de Chile,

Santiago, Chile; ${ }^{6}$ Department of

Chiropractic, Macquarie University,

Sydney, Australia
Correspondence: Roger M Engel Department of Chiropractic, Macquarie University, Sydney, NSW 2109, Australia

Tel +6I 298506387

Fax +6I 298509389

Email roger.engel@mq.edu.au
Background and objective: In chronic obstructive pulmonary disease (COPD), accessory respiratory muscles are recruited as a compensatory adaptation to changes in respiratory mechanics. This results in shortening and overactivation of these and other muscles. Manual therapy is increasingly being investigated as a way to alleviate these changes. The aim of this study was to measure the immediate effect on lung function of a soft tissue manual therapy protocol (STMTP) designed to address changes in the accessory respiratory muscles and their associated structures in patients with severe COPD.

Methods: Twelve medically stable patients $(n=12)$ with an existing diagnosis of severe COPD (ten: GOLD Stage III and two: GOLD Stage IV) were included. Residual volume, inspiratory capacity and oxygen saturation $\left(\mathrm{SpO}_{2}\right)$ were recorded immediately before and after administration of the STMTP. A Student's $t$-test was used to determine the effect of the manual therapy intervention $(P<0.05)$.

Results: The mean age of the patients was 62.4 years (range 46-77). Nine were male. Residual volume decreased from 4.5 to $3.9 \mathrm{~L}(P=0.002)$, inspiratory capacity increased from 2.0 to $2.1 \mathrm{~L}$ $(P=0.039)$ and $\mathrm{SpO}_{2}$ increased from $93 \%$ to $96 \%(P=0.001)$.

Conclusion: A single application of an STMTP appears to have the potential to produce immediate clinically meaningful improvements in lung function in patients with severe and very severe COPD.

Keywords: expiratory reserve volume, plethysmography, residual volume, inspiratory capacity

\section{Introduction}

Chronic obstructive pulmonary disease (COPD) is a common preventable and treatable disease characterized by progressive airflow limitation that is associated with an inflammatory response to noxious particles or gases. ${ }^{1}$ The disease has been categorized in to four stages according to severity: mild, moderate, severe and very severe. ${ }^{2}$ Exacerbations and comorbidities contribute to the overall severity in individual patients with the disease affecting not only the respiratory system but also the musculoskeletal system. ${ }^{2,3}$

In COPD, changes in the anatomy of the airways and lung parenchyma occur as the result of bronchial hypersecretion and bronchoalveolar instability. These changes cause expiratory flow limitation and air trapping, known clinically as dynamic hyperinflation. This phenomenon leads to increases in expiratory reserve volume, residual volume (RV) and end expiratory lung volume (EEV). The increase in EEV limits tidal and inspiratory reserve volumes resulting in a negative impact on inspiratory capacity (IC). ${ }^{4}$ The changes alter the position of the ribs causing a state similar to sustained 
inspiration over time, often referred to as "inspiratory block". This phenomenon is responsible for the characteristic "barrel chest" commonly seen in patients with COPD. In this state, the position of the diaphragm is flattened and shortened reducing its ability to generate force. ${ }^{5}$ Accessory respiratory muscles are recruited as a compensatory adaptation leading to shortening and overactivation of these muscles over time (overadaptation). ${ }^{5}$ The surrounding cervicothoracic fascia contracts producing postural changes, such as anterior projection of the head, neck hyperextension, increased thoracic kyphosis and internal rotation of shoulders. These changes contribute to an increase in chest tightness, a decrease in the ability to generate inspiratory pressures and volumes and an increase in the amount of effort required to breathe..$^{5-7}$

Current COPD management strategies include physical activity and respiratory muscle training. ${ }^{2}$ Physical activity improves exercise tolerance, whereas respiratory muscle training increases inspiratory muscle strength. Targeting disturbances in the respiratory pumping mechanism is not part of this approach making the addition of a therapeutic intervention that directly addresses the soft tissues of the chest wall a novel approach.

Manual therapy (MT) has been described as a therapeutic intervention that uses the hands to provide treatment to the musculoskeletal and/or visceral systems. ${ }^{8}$ MT includes techniques such as massage, myofascial release, muscle energy technique, ligament balance, joint mobilization and joint manipulation. The suggestion that MT can deliver ongoing benefits for people with COPD has been proposed in the literature. ${ }^{9}$ Since then, a number of small studies have reported improvements in lung function and/or exercise capacity following various forms of MT intervention over the immediate, short- and medium terms. ${ }^{10-15}$

Two of these studies measured the immediate effect of MT on lung function: one measured the effect of a single session of soft tissue therapy in combination with thoracic mobilization, ${ }^{10}$ whereas the other measured the effect of six sessions of a single soft tissue technique - the manual diaphragm release technique. ${ }^{13}$ Neither study was capable of clearly delineating the effect of a single session of soft tissue MT on lung function.

The aim of this study was to measure the immediate effect on lung function of a single session of soft tissue MT.

\section{Patients and methods}

Clinical records from patients who attended the outpatient clinic of San José Hospital in Santiago, Chile, were screened for suitability for inclusion in the study. To be included, a patient had to have a diagnosis of severe or very severe COPD (GOLD: Stage III or IV) ${ }^{1}$ and be medically stable with no exacerbations in the preceding 2 months. Patients were excluded from the study if they had any of the following: a rheumatoid condition, neuromuscular or musculoskeletal pathology, cognitive disability that could affect their understanding or execution of the assessment tests or intervention protocol, supplemental oxygen dependency, or previous or current enrollment in a pulmonary rehabilitation program.

Patients who met these conditions were invited to attend an educational session explaining the purpose of the study, proposed outcome assessments and the soft tissue manual therapy protocol (STMTP) used in the trial. After providing written consent, a patient was enrolled in the study.

Baseline measurements, including age, weight, height and lung volumes, were recorded. Lung volumes were measured using body plethysmography (Sensormedics VMAX 22 Pulmonary Function Test System; SensorMedics Corporation, Yorba Linda, CA, USA) and collected according to the standards and procedures outlined by the American Thoracic Society. ${ }^{3}$ Lung volumes included total lung capacity (TLC), vital capacity (VC), RV, expiratory reserve volume (ERV), IC and airway resistance $\left(\mathrm{R}_{\mathrm{aw}}\right)$.

Heart rate (HR) was assessed manually through palpation of the radial pulse for 1 minute with the patient at rest. Respiratory rate (RR) was measured using the direct observation method and calculated by counting the number of respiratory cycles in 1 minute while the patient was at rest. Oxygen saturation $\left(\mathrm{SpO}_{2}\right)$ was measured using a portable finger oximeter (Prince 100I; Heal Force Bio-meditech Holdings Limited, Hong Kong, People's Republic of China) with the patient at rest. All measurements were taken immediately before and after administration of the STMTP.

\section{MT protocol}

The STMTP used in this trial consisted of a pre-determined set of seven soft tissue techniques delivered as part of a single treatment session lasting $\sim 30$ minutes (Table 1). The techniques and their respective durations were sub-occipital release, 5 minutes; anterior thoracic myofascial and sternum release, 5 minutes; anterior cervical myofascial release, 5 minutes; costal ligament balance, 5 minutes; and muscular energy technique to the following muscles: scalenes, 1 minute and 40 seconds, pectoralis minor, 1 minute and 40 seconds and latisimus dorsi and serratus anterior, 1 minute and 40 seconds. All techniques were administered in the same order and by a single therapist with the patient positioned in Fowler's position $\left(45^{\circ}\right)$ throughout the session. 
Table I Soft tissue manual therapy protocol

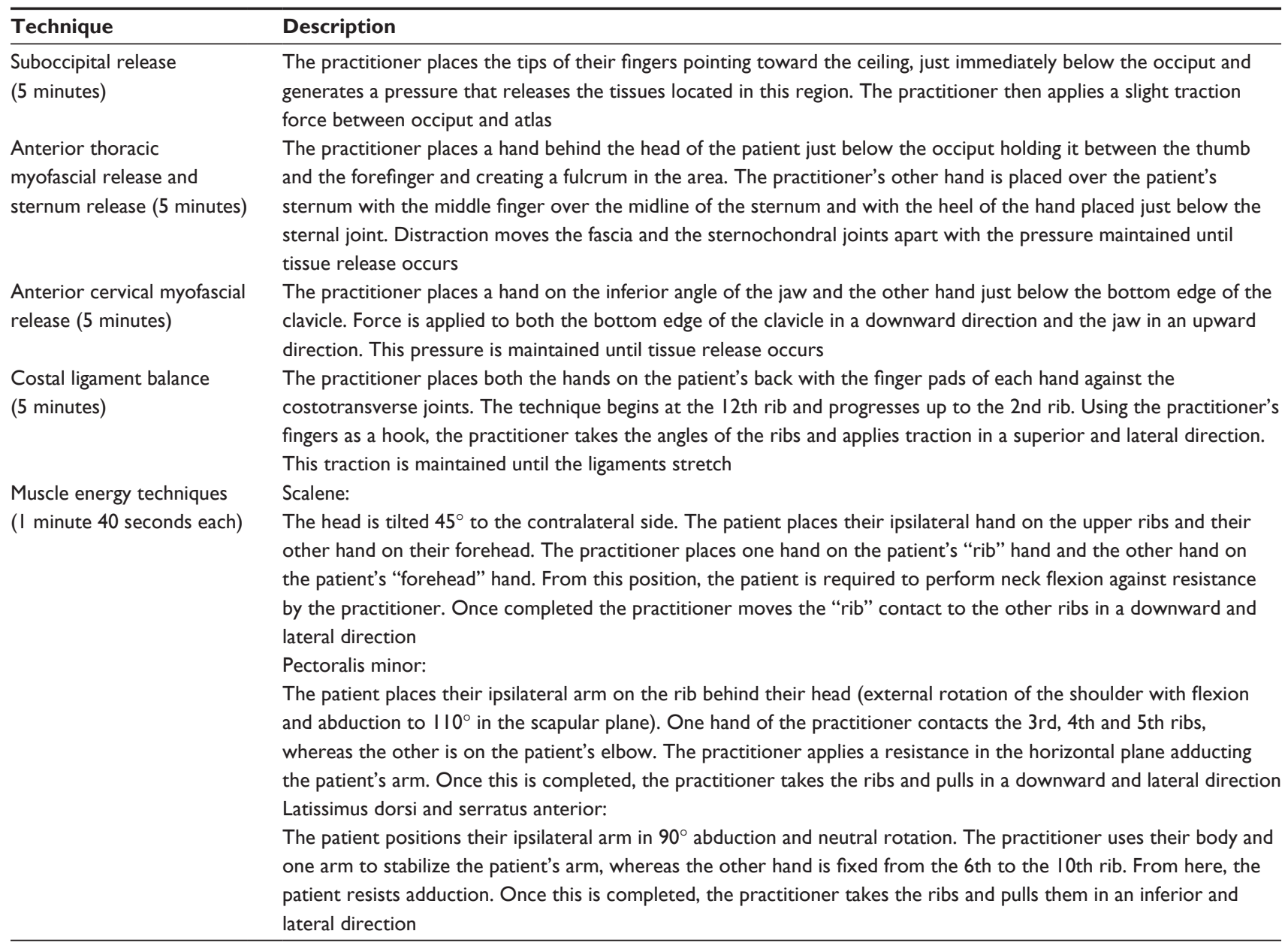

Statistical analysis was performed using the SPSS 15.0 software (SPSS for Windows Version 15.0; SPSS Inc, Chicago, IL, USA). Normal distributions for HR, RR, $\mathrm{SpO}_{2}$ and lung volumes were assessed using the Shapiro-Wilk test $(P>0.05)$. A Student's $t$-test for comparison before and after intervention was used to determine the effect of the STMTP. A $P$-value of $<0.05$ was set as the threshold for statistical significance.

The Metropolitan North Health Service of Santiago, Chile, approved the study and all participants provided written informed consent to participate in the study. The trial was registered with the US National Institutes of Health (Trial registration number: NCT02534831). The research was conducted in accordance with the Declaration of Helsinki.

\section{Results}

A total of 300 clinical records were reviewed as part of this trial. Twenty-five met the inclusion/exclusion criteria, and these patients were invited to participate in the study. Thirteen participants did not complete the study either through non-attendance or through incomplete assessments. Patient flow through the study is outlined in Figure 1. Ten patients had severe (GOLD Stage III) and two had very severe (GOLD Stage IV) COPD. Nine were males. The mean age was $62.4 \pm 7.8$ years, mean weight was $71.8 \pm 9.3 \mathrm{~kg}$ and mean height was $164 \pm 6.1 \mathrm{~cm}$ (Table 2). Table 3 shows the pre- and postintervention measurements for HR, RR and $\mathrm{SpO}_{2}$ for all 12 patients who completed the study. Average HR decreased from $83.8 \pm 14.1$ beats per minute (bpm) preintervention to $76.5 \pm 15.3 \mathrm{bpm}$ postintervention $(P=0.001)$; RR decreased from $20.4 \pm 4.3$ respirations per minute (rpm) preintervention to $15.7 \pm 3.8 \mathrm{rpm}$ postintervention $(P=0.001)$ and $\mathrm{SpO}_{2}$ increased from $92.8 \% \pm 2.8 \%$ preintervention to $95.8 \% \pm 2.4 \%$ postintervention $(P=0.001)$. TLC decreased by $0.4 \mathrm{~L}$ (pre: $6.8 \pm 2.0$; post: $6.4 \pm 1.8 ; P=0.031$ ), ERV by $0.05 \mathrm{~L}(0.33 \pm 0.17 ; 0.28 \pm 0.16 ; P=0.005)$ and $\mathrm{RV}$ by $0.6 \mathrm{~L}(4.5 \pm 1.5 ; 3.9 \pm 1.4 ; P=0.002)$, whereas IC increased by $0.1 \mathrm{~L}(2.0 \pm 0.5 ; 2.1 \pm 0.6 ; P=0.039$; Figure 2$)$. There were no changes in $\mathrm{VC}$ and $\mathrm{R}_{\mathrm{aw}}(P=0.799$ and $P=0.068$, respectively). 


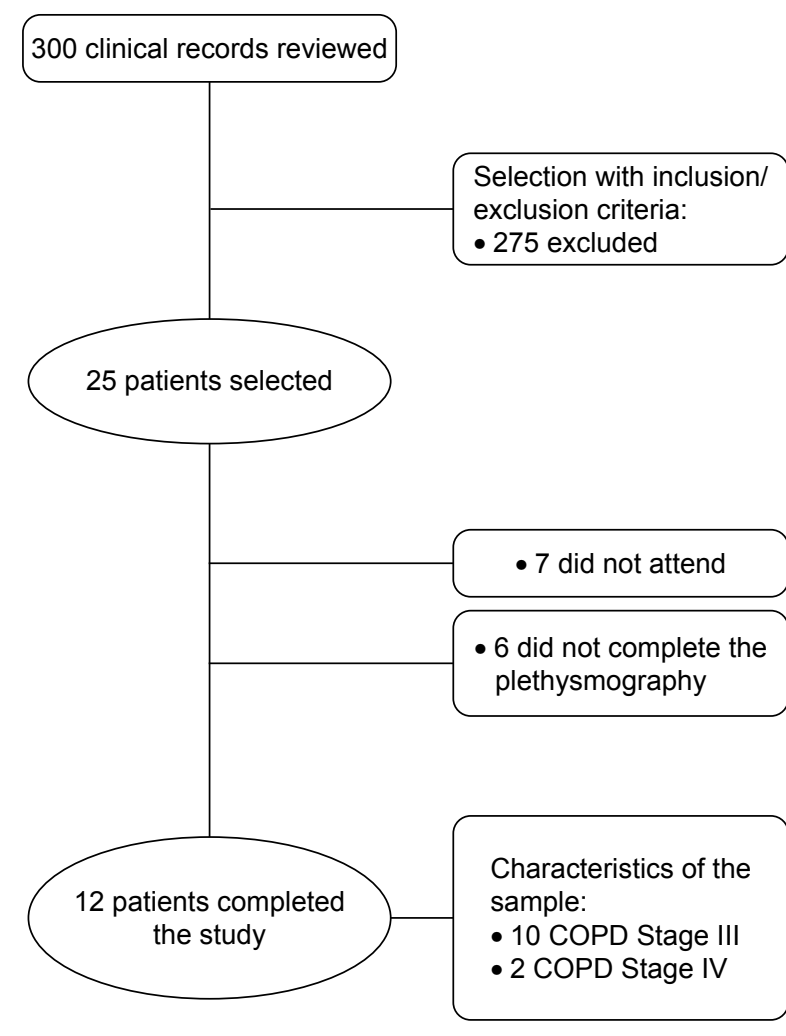

Figure I CONSORT flow diagram.

Abbreviation: COPD, chronic obstructive pulmonary disease.

\section{Discussion}

Results from this study show that a single application of a soft tissue MT protocol designed to address the soft tissues of the chest wall has the potential to produce immediate improvements in lung function in patients with severe and very severe COPD. Furthermore, the reduction in RV may prove to be clinically relevant as it was above the threshold for minimal important difference. ${ }^{16}$

The results from this study are in line with results from a similar study that reported immediate improvements in lung function after a single session of MT. ${ }^{10}$ However, that trial used an MT protocol that included a combination of soft tissue therapy and thoracic mobilization. In using only soft tissue

Table 2 Demographic and clinical characteristics of participants

\begin{tabular}{ll}
\hline Characteristics & Mean \pm SD \\
\hline Male/female $(\mathrm{n})$ & $9 / 3$ \\
Age, years & $62.4 \pm 7.8$ \\
Weight $(\mathrm{kg})$ & $71.8 \pm 9.3$ \\
Height $(\mathrm{m})$ & $1.64 \pm 0.06$ \\
BMI $\left(\mathrm{kg} / \mathrm{m}^{2}\right)$ & $26.6 \pm 2.2$ \\
GOLD Stage III/IV $(\mathrm{n})$ & $10 / 2$ \\
Smoking (pack-years) & $38.1 \pm 22.4$ \\
Smoking status nonsmoker/ex-smoker/smoker $(\mathrm{n})$ & $3 / 9 / 0$ \\
\hline
\end{tabular}

Abbreviations: BMI, body mass index; GOLD, Global Initiative for Obstructive Lung Disease; SD, standard deviation.
Table 3 Pre- and postintervention outcome measurements ${ }^{\mathrm{a}}$

\begin{tabular}{|c|c|c|c|c|c|c|}
\hline \multirow[t]{2}{*}{ Patient } & \multicolumn{2}{|c|}{ HR (bpm) } & \multicolumn{2}{|c|}{ RR (rpm) } & \multicolumn{2}{|c|}{$\mathrm{SpO}_{2}(\%)$} \\
\hline & Pre & Post & Pre & Post & Pre & Post \\
\hline I & 65 & 60 & 18 & 12 & 95 & 98 \\
\hline 2 & 88 & 80 & 16 & 10 & 92 & 96 \\
\hline 3 & 81 & 76 & 18 & 14 & 90 & 94 \\
\hline 4 & 84 & 72 & 14 & 12 & 93 & 97 \\
\hline 5 & 88 & 80 & 16 & 12 & 96 & 98 \\
\hline 6 & 83 & 74 & 22 & 18 & 92 & 96 \\
\hline 7 & 112 & 110 & 21 & 17 & 86 & 90 \\
\hline 8 & 104 & 99 & 24 & 18 & 94 & 97 \\
\hline 9 & 72 & 66 & 30 & 24 & 91 & 93 \\
\hline 10 & 87 & 80 & 22 & 18 & 93 & 95 \\
\hline II & 63 & 60 & 22 & 16 & 96 & 99 \\
\hline 12 & 78 & $6 I$ & 22 & 17 & 95 & 96 \\
\hline Average & 83.8 & 76.5 & 20.4 & 15.7 & 92.8 & 95.8 \\
\hline
\end{tabular}

Note: aAll measurements given as means.

Abbreviations: bpm, beats per minute; HR, heart rate; RR, respiratory rate; rpm, respirations per minute; $\mathrm{SpO}_{2}(\%)$, percentage oxygen saturation.

MT, the most likely cause of the improvements reported in our study is a reduction in chest tightness produced by soft tissue MT intervention. This is in line with results from other studies that showed that soft tissue MT was capable of reducing hypertonicity in myofascial tissues when applied to other areas of the body ${ }^{17-22}$ Reduced tonicity in the muscles, fascia and ligaments of the neck and chest would facilitate an improvement in the passive components of expiration by reducing the extent of any inspiratory block. In support of this concept are the results from a recent exploratory study, which reported a correlation between pulmonary function, postural alignment and mobility of the upper quadrant in patients with COPD..$^{23}$

The decreases in ERV and RV can be directly attributed to the increase in IC as it would return the inspiratory muscles closer to their optimal length, thereby improving mechanical efficiency. ${ }^{4,5}$ Improvements in mechanical efficiency may also explain the increase in $\mathrm{SpO}_{2}$ and decrease in $\mathrm{RR}$, which if sustainable, could alter input to the central and peripheral chemoreceptors. ${ }^{24,25}$ The decrease in HR may be the result of a flow-on effect from a decreasing RV where lower pressure within the lungs leads to a reduction in pulmonary hypertension..$^{24,26,27}$ The absence of any changes in $\mathrm{VC}$ and $\mathrm{R}_{\mathrm{aw}}$ may simply be the result of the small size of the changes in RV, ERV, TLC and IC.

It is worth noting that the TLC values reported in this study were higher than those traditionally reported in patients with severe and very severe COPD. This may be due to two reasons: (1) patients with COPD and lung hyperinflation can have a TLC that is $>100 \%$ of the predicted value, ${ }^{4}$ and (2) spirometric values for the Chilean population have been reported as being higher than in other populations. ${ }^{28}$ 

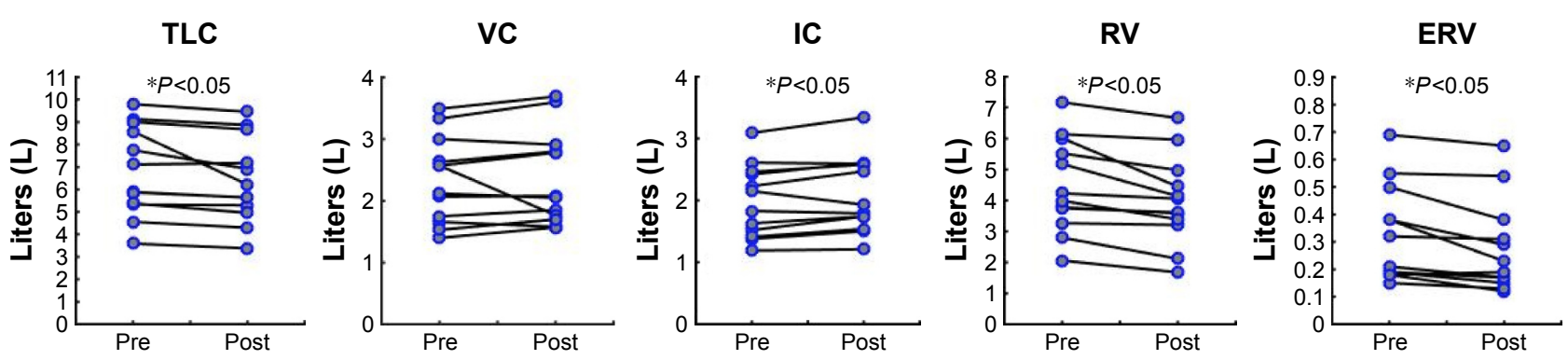

Figure 2 Changes in lung volume and capacities pre- and postintervention.

Note: *Statistical significance: $P<0.05$.

Abbreviations: ERV, expiratory reserve volume; IC, inspiratory capacity; pre, preintervention; post, postintervention; RV, residual volume; TLC, total lung capacity; VC, vital capacity.

Although the findings from a recent systematic review into the effect of MT on COPD were inconclusive with respect to benefiting lung function, ${ }^{29}$ technique choice may have played a role in influencing this view as MT techniques that use compression/decompression maneuvers can increase airway obstruction by accelerating airflow to the extent that airways collapse. ${ }^{4}$ Patient positioning during the STMTP may have influenced our results as having the patient supine for an extended period of time can increase the effect of inefficient diaphragm motion. The way lung function was measured may also have influenced the results. Although the previous study used spirometry to assess lung function and focused on measures, such as forced expiratory volume in the first second and forced vital capacity, ${ }^{10}$ we used plethysmography and were, therefore, able to measure changes in RV accurately, which directly relate to the extent of dynamic hyperinflation. ${ }^{30-32}$

The MT techniques used in this study were chosen because of their potential to reduce the effects of overactivation and overadaptation in the respiratory muscles. The results reported here are supported by results in other studies, involving the administration of MT to patients with COPD. These studies used a similar approach in producing short-term ${ }^{11-13,15}$ and medium-term ${ }^{14}$ improvements in lung function. Notwithstanding, to our knowledge, this is the first study to use plethysmography to report a clinically meaningful reduction in RV following MT intervention.

The STMTP could be used in a repeated manner as part of a pulmonary rehabilitation program for patients with COPD. As it has the potential to reduce overactivation in the respiratory muscles, it may also be beneficial following an exacerbation.

\section{Limitations}

Apart from the recognized limitations associated with a study design of this nature, there are a number of other limitations associated with this study. Gender mix differences may have altered the statistical analyses as males and females have different lung volumes. The contribution toward the decreases in HR and RR of leaving the patient in Fowler's position for an extended period of time (30 minutes) is unclear. By not gathering data on adverse events, the safety of this STMTP remains unknown. As a study aimed at evaluating the immediate effect of a specific intervention, the impact of these limitations should be considered within this context and not measured against other study designs.

\section{Conclusions}

A single application of an MT protocol consisting of seven soft tissue techniques has the potential to deliver immediate improvements in lung function for people with severe and very severe COPD. The results from this study support the call for further research in the field on larger cohorts that include multiple measuring points and a control group. Such studies would help to confirm if the benefits reported here can be sustained in patients with advanced COPD.

\section{Authors' contribution}

CCM helped in concept, design, data collection, analysis and interpretation, drafting and revising the manuscript; DGO contributed to design, data collection, analysis and interpretation, drafting and revising the manuscript; FACB performed data analysis and interpretation, drafting and revising the manuscript; PG carried out design, data collection, analysis and interpretation, drafting and revising the manuscript; RTC helped in data analysis and interpretation, drafting and revising the manuscript; LMV carried out design, data collection, analysis and interpretation, drafting and revising the manuscript; RME contributed to data interpretation, drafting and revising the manuscript. All authors gave final approval of this version to be published and agreed to be accountable for all aspects of the work and for ensuring that questions related to the accuracy or integrity of any part of the work are appropriately investigated and resolved. 


\section{Disclosure}

The authors report no conflicts of interest in this work.

\section{References}

1. Vestbo J, Hurd SS, Agustí AG, et al. Global strategy for the diagnosis, management, and prevention of chronic obstructive pulmonary disease: GOLD executive summary. Am J Respir Crit Care Med. 2013; 187(4):347-365.

2. Spruit MA, Watkins ML, Edwards LD, et al; Evaluation of COPD Longitudinally to Identify Predictive Surrogate Endpoints (ECLIPSE) study investigators. Determinants of poor 6-min walking distance in patients with COPD: the ECLIPSE cohort. Respir Med. 2010; 104(6):849-857.

3. Miller MR, Hankinson J, Brusasco V, et al; ATS/ERS Task Force. Standardisation of spirometry. Eur Respir J. 2005;26(2):319-338.

4. O'Donnell D, Laveneziana P. Physiology and consequences of lung hyperinflation in COPD. Eur Respir Rev. 2006;15(100):61-67.

5. Orozco-Levi M. Structure and function of the respiratory muscles in patients with COPD: impairment or adaptation? Eur Respir J Suppl. 2003;46:41s-51s.

6. Chaitow L, DeLany J. Clinical Application of Neuromuscular Techniques: The Upper Body. 2nd ed. Edinburgh, UK: Elsevier Health Sciences; 2008.

7. Dias C, Kirkwood R, Parreira V, Sampaio R. Orientation and position of the scapula, head and kyphosis thoracic in male patients with COPD. Can J Resp Ther. 2009;45(2):30-34.

8. Pettman E. A history of manipulative therapy. J Man Manip Ther. 2013;21:165-174.

9. Engel RM, Vemulpad S. Progression to chronic obstructive pulmonary disease (COPD): could it be prevented by manual therapy and exercise during the 'at risk' stage (stage 0)? Med Hypotheses. 2009;72(3): 288-290.

10. Yelvar GDY, Çirak Y, Demir YP, Dalkilinç M, Bozkurt B. Immediate effect of manual therapy on respiratory functions and inspiratory muscle strength in patients with COPD. Int J Chron Obstruct Pulmon Dis. 2016;11:1353-1357.

11. Dougherty PE, Engel RM, Vemulpad S, Burke J. Spinal manipulative therapy for elderly patients with chronic obstructive pulmonary disease: a case series. J Manipulative Physiol Ther. 2011;34(6):413-417.

12. Engel RM, Vemulpad SR, Beath K. Short-term effects of a course of manual therapy and exercise in people with moderate chronic obstructive pulmonary disease: a preliminary clinical trial. J Manipulative Physiol Ther. 2013;36(8):490-496.

13. Rocha T, Souza H, Brandão DC, et al. The manual diaphragm release technique improves diaphragmatic mobility, inspiratory capacity and exercise capacity in people with chronic obstructive pulmonary disease: a randomised trial. J Physiother. 2015;61(4):182-189.

14. Engel RM, Gonski P, Beath K, Vemulpad S. Medium term effects of including manual therapy in a pulmonary rehabilitation program for chronic obstructive pulmonary disease (COPD): a randomized controlled pilot trial. J Man Manip Ther. 2016;24(2):80-89.

15. Zanotti E, Berardinelli P, Bizzarri C, et al. Osteopathic manipulative treatment effectiveness in severe chronic obstructive pulmonary disease: a pilot study. Complement Ther Med. 2012;20(1):16-22.
16. Hartman JE, Ten Hacken NH, Klooster K, Boezen HM, de Greef $\mathrm{MH}$, Slebos DJ. The minimal important difference for residual volume in patients with severe emphysema. Eur Respir J. 2012;40(5): $1137-1141$.

17. Cho SH, Kim SH, Park DJ. The comparison of the immediate effects of application of the suboccipital muscle inhibition and self-myofascial release techniques in the suboccipital region on short hamstring. JPhys Ther Sci. 2015;27(1):195-197.

18. Aparicio ÉQ, Quirante LB, Blanco CR, Sendín FA. Immediate effects of the suboccipital muscle inhibition technique in subjects with short hamstring syndrome. J Manipulative Physiol Ther. 2009;32(4):262-269.

19. Krause F, Wilke J, Vogt L, Banzer W. Intermuscular force transmission along myofascial chains: a systematic review. J Anat. 2016;228(6): 910-918.

20. Wilke J, Krause F, Vogt L, Banzer W. What is evidence-based about myofascial chains: a systematic review. Arch Phys Med Rehabil. 2016; 97(3):454-461.

21. Cruz-Montecinos C, Cerda M, Sanzana-Cuche R, Martín-Martín J, Cuesta-Vargas A. Ultrasound assessment of fascial connectivity in the lower limb during maximal cervical flexion: technical aspects and practical application of automatic tracking. BMC Sports Sci Med Rehabil. 2016;8:18.

22. Cruz-Montecinos C, Gonzalez Blanche A, Lopez Sanchez D, et al. In vivo relationship between pelvis motion and deep fascia displacement of the medial gastrocnemius: anatomical and functional implications. J Anat. 2015;227(5):665-672.

23. Morais N, Cruz J, Marques A. Posture and mobility of the upper body quadrant and pulmonary function in COPD: an exploratory study. Braz J Phys Ther. 2016;20(4):345-354.

24. Chaouat A, Naeije R, Weitzenblum E. Pulmonary hypertension in COPD. Eur Respir J. 2008;32(5):1371-1385.

25. West JB. Respiratory Physiology: The Essentials. 9th ed. Baltimore, MD: Lippincott Williams \& Wilkins; 2012.

26. Naeije R. Pulmonary hypertension and right heart failure in chronic obstructive pulmonary disease. Proc Am Thorac Soc. 2005;2(1): $20-22$.

27. Wright J, Levy R, Churg A. Pulmonary hypertension in chronic obstructive pulmonary disease: current theories of pathogenesis and their implications for treatment. Thorax. 2005;60(7):605-609.

28. Gutiérrez M, Valdivia G, Villarroel L, et al. Proposición de nuevas ecuaciones para calcular valores espirométricos de referencia en población chilena adulta: Sociedad Chilena de Enfermedades Respiratorias (SER) [Proposition of new equations for calculating reference spirometric values in the Chilean adult population: Chilean Society of Respiratory Diseases (SRD)]. Rev Med Chile. 2014;142(2):143-152. Spanish.

29. Heneghan NR, Adab P, Balanos GM, Jordan RE. Manual therapy for chronic obstructive airways disease: a systematic review of current evidence. Man Ther. 2012;17(6):507-518.

30. Hankinson J, Stocks J, Peslin R. Reproducibility of lung volume measurements. Eur Respir J. 1998;11(3):787-790.

31. Hughes JM, Pride NB. Lung Function Tests: Physiological Principles and Clinical Applications. London, UK: Bailliere Tindall; 1999.

32. Piatti G, Fasano V, Cantarella G, Tarantola C. Body plethysmographic study of specific airway resistance in a sample of healthy adults. Respirology. 2012;17(6):976-983.
International Journal of COPD

\section{Publish your work in this journal}

The International Journal of COPD is an international, peer-reviewed journal of therapeutics and pharmacology focusing on concise rapid reporting of clinical studies and reviews in COPD. Special focus is given to the pathophysiological processes underlying the disease, intervention programs, patient focused education, and self management protocols.
Dovepress

This journal is indexed on PubMed Central, MedLine and CAS. The manuscript management system is completely online and includes a very quick and fair peer-review system, which is all easy to use. Visit $\mathrm{http}: / / \mathrm{www}$.dovepress.com/testimonials.php to read real quotes from published authors. 